\title{
Spheromak magnetic fusion energy power plant with thick liquid-walls*
}

\author{
R. W. Moir ${ }^{\mathrm{a}}$, R. H. Bulmer ${ }^{\mathrm{a}}$, T. K. Fowler ${ }^{\mathrm{b}}$, T. D. Rognlien ${ }^{\mathrm{a}}$, \& M. Z. Youssef ${ }^{\mathrm{c}}$ \\ ${ }^{a}$ Lawrence Livermore National Laboratory, Livermore, CA \\ bUniversity of California at Berkeley, Berkeley, CA \\ 'University of California at Los Angeles, Los Angeles, CA
}

\begin{abstract}
A power plant based on a spheromak device using liquid walls is analyzed. We assume a spheromak configuration can be made and sustained by a steady plasma gun current, which injects particles, current and magnetic field, i.e., helicity injection, which are transported into the core region. The magnetic configuration is evaluated with an axisymmetric freeboundary equilibrium code, where the current profile is tailored to support an average beta of $10 \%$. An injection current of $100 \mathrm{kA}$ (125 MW of gun power) sustains the toroidal current of $40 \mathrm{MA}$. The magnetic flux linking the gun is $1 / 1000^{\text {th }}$ of the flux in the spheromak. The geometry allows a flow of liquid, either molten salt, (flibe- $\mathrm{Li}_{2} \mathrm{BeF}_{4}$ or flinabe- $\mathrm{LiNaBeF}_{4}$ ), or liquid metal such as $\mathrm{SnLi}$, which protects most of the walls and structures from damage arising from neutrons and plasma particles. The free surface between the liquid and the burning plasma is heated primarily by bremsstrahlung, line radiation, and some by neutrons. The temperature of the free surface of the liquid is calculated and then the evaporation rate is estimated from vaporpressure data. The impurity concentration in the burning plasma, about $0.8 \%$ fluorine, is limited to that giving a $20 \%$ reduction in the fusion power. The divertor power density of $620 \mathrm{MW} / \mathrm{m}^{2}$ is handled by high-speed $(100 \mathrm{~m} / \mathrm{s})$ liquid jets. Calculations show the tritium breeding is adequate with enriched ${ }^{6} \mathrm{Li}$, and a design is given for the walls not covered by flowing liquid ( $15 \%$ of the total). We identified a number of problem areas needing further study to make the design more self-consistent and workable, including lowering the divertor power density by expanding the flux tube size.
\end{abstract}

\section{Introduction and background}

This paper summarizes a power plant design study that applies liquid walls to the steady state spheromak plasma confinement configuration[1]. The spheromak idea came about by a number of routes[2]. The toroidal coils of the tokamak might not be necessary if the plasma could carry enough current to make a sufficient toroidal and poloidal fields. In this case, the performance might be tokamak-like with a simpler magnet configuration. Early experiments were encouraging. Hagenson and Krakowski made a reactor design [3]. Other reactor studies included solid first walls and boiling liquid blankets [4] and pulsed liquid walls [5]. Physics opportunities and issues of the reactor are discussed in [6]. The components of the design and organization of this paper follows:

- the configuration is based on MHD equilibrium calculations

- a steady-state gun is used for helicity injection for current drive

- the plasma and other related parameters are given

- the electrodes and insulators are described

- the liquid wall flows are described, the surface temperatures are calculated (based on incident power on the liquid surface and interior heating)

- the evaporation rates from the liquid surfaces that depend only on surface temperature are calculated

- the role of the edge plasma is discussed and estimates of evaporation allowed based on core plasma contamination by impurities are made

- tritium breeding is discussed

We consider low conductivity liquids (molten salts) and high conductivity liquids (liquid metals). The usual molten salt is flibe $\left(\mathrm{Li}_{2} \mathrm{BeF}_{4}\right)$, but past studies show the evaporation limits require temperatures near or below the melt temperature of $460{ }^{\circ} \mathrm{C}$. Adding $\mathrm{NaF}$ to flibe produces flinabe $\left(\mathrm{NaF}+\mathrm{LiF}+\mathrm{BeF}_{2}\right.$ $=\mathrm{LiNaBeF}_{4}$ ) [7], whose melt temperature is reduced to $\sim 310{ }^{\circ} \mathrm{C}$. This study is based on flinabe as a candidate molten salt. SnLi is the liquid metal candidate. There are many aspects of the design that need further work. These are discussed throughout the report. 


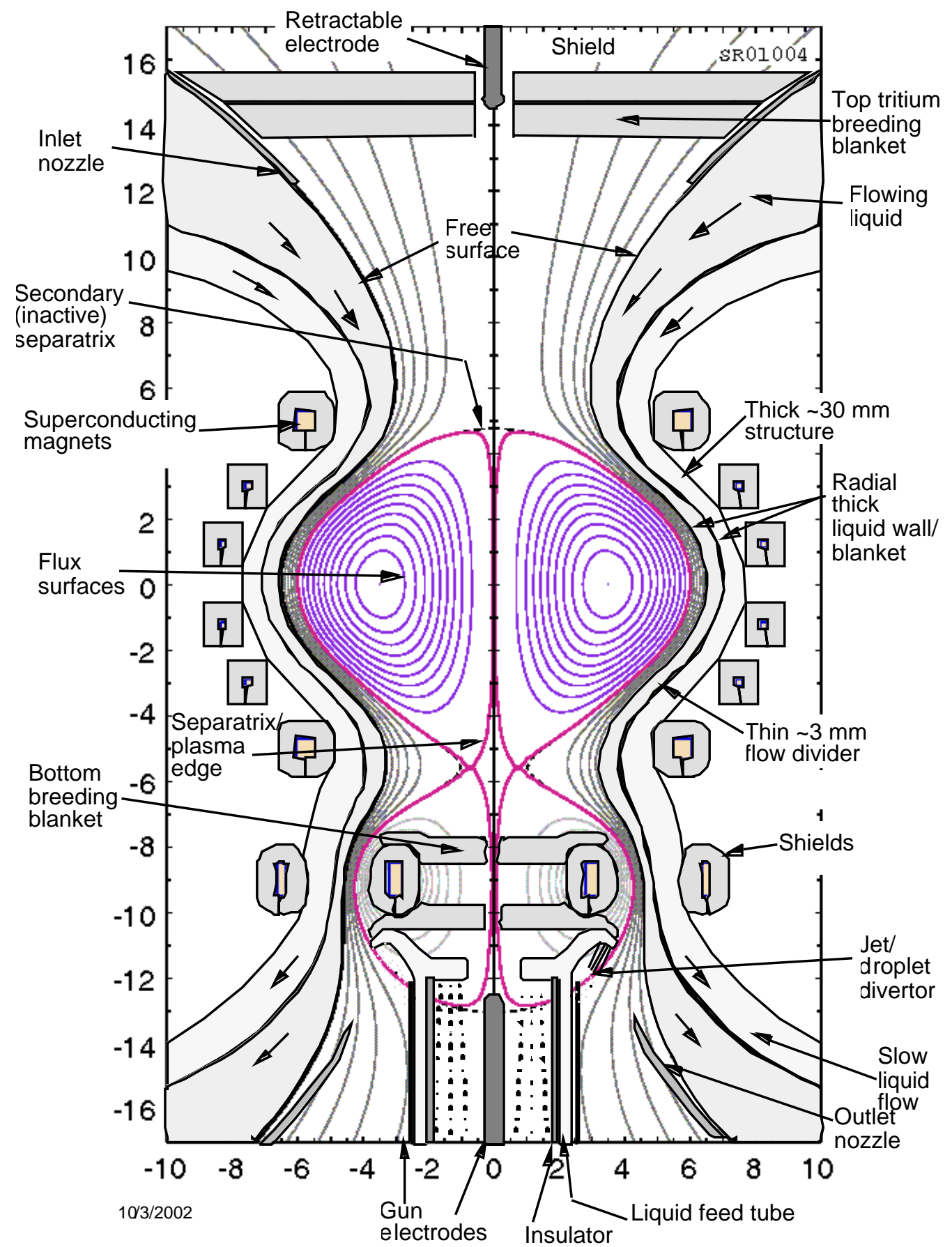

Fig. 1. The spheromak configuration with liquid walls shown above is the subject of this report. The liquid flow is kept to the outside by centrifugal force for molten salt and by magnetic guide field for liquid metals. Liquid jets greatly aid divertor heat removal.

\section{Configuration-equilibria}

The spheromak reactor shown in Fig. 1 was developed with the Corsica code[8]. The freeboundary equilibrium is designed to have a magnetic flux amplification factor of 1000 with an elongation less than 2 to mitigate instabilities. Of particular concern are tilt and shift modes, which will probably require [9] active feedback coils. These coils are envisioned to be relatively small and located near the inner surface of the shielding structure facing the plasma in the confined region.

The distance from the outer edge of the plasma to the first solid conducting wall is $1 \mathrm{~m}$ in the case of flinabe 
( $0.5 \mathrm{~m}$ from the plasma edge to the low conductivity flinabe and $0.5 \mathrm{~m}$ of flinabe to the $30-\mathrm{mm}$ thick stainless steel wall). In the case of SnLi the conducting liquid wall is $0.5 \mathrm{~m}$ from the plasma.

The current profile deviates from the relaxed Taylorstate in that the $\lambda$-profile (normalized current density, see [2]):

$\lambda(\psi)=\frac{\mu_{0} \mathbf{j} \cdot \mathbf{B}}{B^{2}}$

varies as shown in Fig. 2, creating shear consistent with a Mercier plasma beta limit of $\frac{p}{B^{2} / 2 \mu_{0}}=0.1$.

The value of $\lambda$ on the open field-lines is about half that at the magnetic axis. The pressure profile shown in Fig.2, has been optimized to yield the maximum Mercier limit for the given $\lambda$-profile. The $q$-profile $\left(q=\left\langle\frac{B_{\varphi}}{B_{z}} \frac{r}{R}\right\rangle\right)$ varies from 0.9 on the magnetic axis to 0.3 near the edge.

The main equilibrium parameters are summarized in Table 1. Note the gun current in the equilibrium model, $18.2 \mathrm{kA}$, is significantly less than the $100-\mathrm{kA}$ value discussed later in the gun section. This discrepancy is due to the particular values of the toroidal current and the ratio of $\lambda_{\text {ext }} / \lambda_{0}$ used in the equilibrium model, and needs to be resolved as the design evolves.

\section{Plasma parameters}

The Corsica model has a plasma pressure giving a volume-averaged beta of $10 \%$. The field of $5.24 \mathrm{~T}$ on $\mathrm{R}=0$ axis, which corresponds to a $40 \mathrm{MA}$ toroidal current. Based on prior work on the Field Reversed Configuration (FRC) [10], we can scale to get a first approximation of some of the parameters.

\section{Radiation model}

The assumed values for radiation used in this paper are given in Tables 2 and 4 . At an electron temperature of $12 \mathrm{keV}$, impurities from flinabe will be mostly in the highest charge state and, therefore, will produce little line radiation. However, near the lower temperature edge region, there will be increased line radiation.

The radiation from the core will consist of $\sim 85 \%$ bremsstrahlung radiation and $\sim 15 \%$ line radiation (see Fig. 4.10.1 of ref. 11). For an impurity fraction, f, of 0.01 , the radiation fraction $F$ is 0.0286 times the fusion power or 0.143 time the alpha power. This would amount to $71.5 \mathrm{MW}(85 \%$ or $60.8 \mathrm{MW}$ of bremsstrahlung and $15 \%$ or $10.7 \mathrm{MW}$ of line radiation from the core).

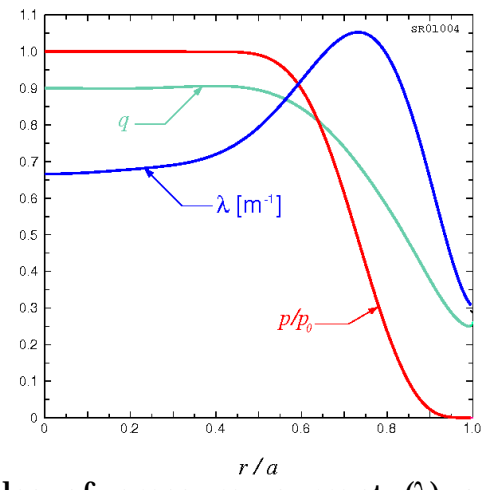

Fig. 2. Profiles of pressure, current $(\lambda)$ and Safety Factor $(\mathrm{q})$ at the midplane.

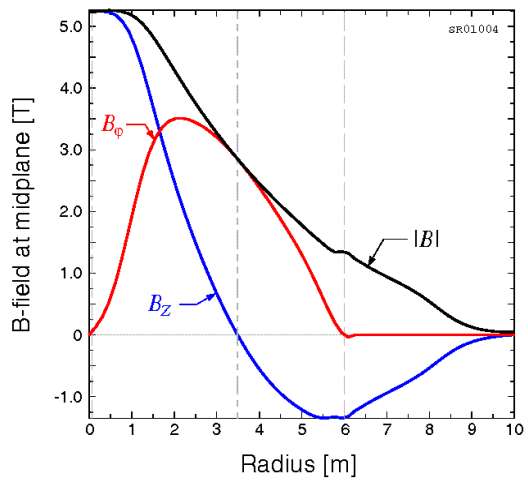

Fig. 3. Magnetic field profile, $B_{\phi}$ and $B_{z}$ are the toroidal and poloidal fields, respectively. The field is consistent with a model having $40 \mathrm{MA}$ toroidal current and beta equal to $10 \%$ volume averaged

Table 1

Equilibrium parameters

\begin{tabular}{|l|l|}
\hline Toroidal current, MA & 40 \\
\hline Toroidal B-field (R=3.49 m), T & 2.89 \\
\hline Poloidal current (gun), kA & 18.2 \\
\hline Poloidal B-field (R=0), $\mathrm{T}$ & 5.24 \\
\hline $\begin{array}{c}\text { Poloidal flux (edge), } \mathrm{Wb} \\
\text { (R=0 to separatrix) }\end{array}$ & 0.08 \\
\hline Poloidal flux (R=0.068 to 3.49 m), $\mathrm{Wb}$ & 75.8 \\
\hline Separatrix radius, inner, $\mathrm{m}$ & 0.068 \\
\hline Separatrix radius, outer, $\mathrm{m}$ & 6.00 \\
\hline Magnetic axis radius, $\mathrm{m}$ & 3.49 \\
\hline Core plasma volume, $\mathrm{m}^{3}$ & 652 \\
\hline Core plasma surface, $\mathrm{m}^{2}$ & 362 \\
\hline Volume average beta, $\%$ & 10 \\
\hline
\end{tabular}

For the UEDGE simulations of the edge plasma, the line radiation from fluorine in the scrape-off layer (SOL) is $1.9 \%$ of the alpha power, or $9.5 \mathrm{MW}$ when the fluorine level at the core boundary is $1 \%$ of the D$\mathrm{T}$ density there (taken to be $5 \times 10^{19} \mathrm{~m}^{-3}$ ).

Approximately $80 \%$ of this $9.5 \mathrm{MW}$ or $7.6 \mathrm{MW}$ falls on the liquid wall and 1.9 MW is localized to the divertor region. If the fluorine concentration remains constant in the ore at $1 \%$, the fusion power is reduced by $16 \%$ owing to fuel dilution. 
Table 2 Typical spheromak power plant parameters.

\begin{tabular}{|c|c|c|c|}
\hline & Spheromak & \multicolumn{2}{|c|}{ FRC } \\
\hline Liquid wall radius, $m$ & 6.5 & 1.5 & 2.0 \\
\hline Separatrix radius, $m$ & $0.068,6.0$ & 0.39 & 1 \\
\hline Magnetic axis, $\mathrm{m}$ & 3.49 & 0.29 & 0.75 \\
\hline $\begin{array}{l}\text { Separatrix length, outside and } \\
\text { inside, } \mathrm{m}\end{array}$ & 15,10 & 8 & 8 \\
\hline $\begin{array}{l}\text { Liquid flow path length, inlet } \\
\text { nozzle exit nozzle, m }\end{array}$ & 27 & 14 & 14 \\
\hline Core plasma volume, $\mathrm{m}^{3}$ & 652 & 2.6 & 25 \\
\hline Outer plasma area, $\mathrm{m}^{2}$ & 362 & 75 & 100 \\
\hline Average ion temperature, $\mathrm{keV}$ & 12 & 12 & 18 \\
\hline Average ion density, $10^{20} \mathrm{~m}^{-3}$ & 1.64 & 26 & 6.2 \\
\hline Peak ion density, $10^{20} \mathrm{~m}^{-3}$ & $?$ & 31 & 6.8 \\
\hline$\overline{Z_{\text {eff }}}$ & 1.5 & 1.5 & 1.5 \\
\hline $\begin{array}{l}\mathrm{s}=\text { plasma radius / } \\
\text { average larmor radius }\end{array}$ & 1100 & 7.5 & 26 \\
\hline $\begin{array}{l}\text { Helicity current drive, kA } \\
\text { Helicity (Gun) power, MW }\end{array}$ & $\begin{array}{l}100 \\
125\end{array}$ & $\overline{---}$ & $\overline{---}$ \\
\hline Toroidal current, MA & 40 & & 40 \\
\hline Volume-averaged beta & 0.1 & 0.97 & 0.78 \\
\hline $\begin{array}{r}\text { Magnetic field, T,Poloidal@R=0 } \\
\text { Toroidal@R=3.49 } \\
\end{array}$ & $\begin{array}{l}\mathrm{Bz}=5.24 \\
\mathrm{~B} \phi=2.89\end{array}$ & 5.5 & 3.6 \\
\hline $\begin{array}{c}\text { Flux from } \mathrm{r}=0 \text { to the } \\
\text { separatrix, } \mathrm{Wb}\end{array}$ & 0.08 & $\overline{---}$ & --- \\
\hline $\begin{array}{l}\text { Flux from separatrix to mag } \\
\text { axis, } \mathrm{Wb}\end{array}$ & 75.8 & --- & --- \\
\hline Energy confinement time, s & $?$ & 0.08 & 0.33 \\
\hline Ash particle conf. time, $\mathrm{s}$ & $?$ & 0.16 & 0.65 \\
\hline Neutron wall load ave,MW/ $\mathrm{m}^{2}$ & 5.5 & 27 & 18 \\
\hline Surface heat load, MW $/ \mathrm{m}^{2}$ & 0.47 & 1.7 & 1.2 \\
\hline Neutron power, MW & 2000 & 2000 & 1844 \\
\hline $\begin{array}{l}\text { Bremsstrahlung radiation } \\
\text { power }\end{array}$ & $\begin{array}{l}60.8 \mathrm{MW} \\
0.17 \mathrm{MW} / \mathrm{m}^{2}\end{array}$ & 46 & 49 \\
\hline Line radiation, core & $\begin{array}{l}10.7 \mathrm{MW} \\
0.03 \mathrm{MW} / \mathrm{m}^{2}\end{array}$ & --- & --- \\
\hline Line radiation, edge & $\begin{array}{l}\text { 7.6 MW } \\
0.02 \mathrm{MW} / \mathrm{m}^{2}\end{array}$ & 78 & 69 \\
\hline $\begin{array}{l}\text { Power to divertor, } \mathrm{MW} \\
500+125-10.7-7.6=546\end{array}$ & 546 & 415 & 383 \\
\hline Input (Gun) power, MW & $125 @ Q=20$ & 40 & 40 \\
\hline Fusion power, MW & 2500 & 2500 & 2306 \\
\hline Net electric power, MWe & $\sim 1000$ & 1000 & 1000 \\
\hline
\end{tabular}

\section{Current Drive Model}

The magnetized Marshall gun used to create and sustain spheromaks can be represented by an electric circuit in which the helicity injection impedance is approximated by a resistor, $R_{S}[12]$. The gun parameters are given in Table 3.

Table 3. Gun Parameters

\begin{tabular}{|l|l|}
\hline Gun Current, $\mathrm{I}(\mathrm{kA})$ & 100 \\
\hline Helicity injection impedance, $\mathrm{R}_{\mathrm{S}}(\mathrm{m} \Omega)$ & 2.8 \\
\hline Total gun impedance, $\mathrm{R}_{\text {GuN }}(\mathrm{m} \Omega)$ & 6.7 \\
\hline Gun voltage, $\mathrm{I} \mathrm{R}_{\text {Cun }}(\mathrm{V})$ & 670 \\
\hline Power consumed by the gun, $\mathrm{I}^{2} \mathrm{R}_{\text {GuN }}(\mathrm{MW})$ & 67 \\
\hline Gun power supply power, $\mathrm{P}(\mathrm{MW})$ & 125 \\
\hline
\end{tabular}

Limiting the gun power to $125 \mathrm{MW}$, for the nominal fusion gain $\mathrm{Q}=20$ in Table 2 , requires a total impedance $\mathrm{P} / \mathrm{I}=12.5 \mathrm{~m} \Omega$. This calls for a notunreasonable d.c. power supply impedance 12.5 - 6.7
$=5.8 \mathrm{~m} \Omega$ and an overall efficiency to sustain the spheromak $=\mathrm{P}_{\Omega} / \mathrm{P}=14 / 125=11 \%$.

The unknown physics resides in the helicity injection impedance $R_{S}$-the subject of ongoing research in SSPX. The required value $R_{S}=2.8 \mathrm{~m} \Omega$ in Table 3 is consistent with an enhanced resistance model of SSPX [12].

The larger question is whether the instability processes of magnetic tearing and reconnection-thought to underlie the helicity injection impedance characteristic of short pulse experiments to date (milliseconds)-will persist in steady state.

\section{Electrode and insulator design}

The electrodes shown at the bottom of Fig. 1 provide the $100 \mathrm{kA}$ of helicity current drive. Its active area is a disk of about $0.25 \mathrm{~m}$ radius. This gives a current density of $50 \mathrm{~A} / \mathrm{cm}^{2}$. A tapered electrode could reduce this current density and might ease cooling. The insulator is a cylindrical sleeve, of radius $2 \mathrm{~m}$ about $5 \mathrm{~m}$ long, shown near the bottom of Fig. 1. Its purpose is to prevent current from passing across the gap between the center electrode at $R=0.25 \mathrm{~m}$ and the cylindrical electrode at $R \approx 2.2 \mathrm{~m}$. The insulator is shielded from line-of-sight radiation. The neutrons and $x$-rays dose rates to the insulator from indirect radiation need to be calculated to determine the insulator's lifetime.

\section{Power plant considerations}

The power flows are based on prior studies[13]. We assume $2500 \mathrm{MW}$ of fusion power. Of this, $2000 \mathrm{MW}$ is in the form of $14 \mathrm{MeV}$ neutrons. Nuclear reactions in the flinabe blanket are assumed to multiply this by 1.18 , giving $2360 \mathrm{MW}$ thermal power in the blanket. To this we add the incident power of the $500 \mathrm{MW}$ from alpha energy and the helicity injection power all of which is absorbed by the flowing fluid either in the walls or in the divertor. We assume a case with $\mathrm{Q}=\mathrm{P}_{\text {fusion }} / \mathrm{P}_{\text {iniection }}=20$, so $\mathrm{P}_{\text {iniection }}=125 \mathrm{MW}$. The total power going into the flowing fluid is $2985 \mathrm{MW}$.

\section{MW nuclear power in the blanket $500 \mathrm{MW}$ alpha power \\ 125 MW injection power \\ 2985 MW total}

The volumetric flow rate $(\dot{V})$ is given by the speed of $10 \mathrm{~m} / \mathrm{s}$ at the midplane with a $0.5 \mathrm{~m}$ thickness. This gives volume and mass flow rates of

$\dot{V}=2 \pi r \Delta r v=2 \pi 6.5 \cdot 0.5 \cdot 10=204.2 \mathrm{~m}^{3} / \mathrm{s} \quad$ and $\dot{m}_{\text {blanket }}=4.084 \cdot 10^{5} \mathrm{~kg} / \mathrm{s}$ of flinabe flow through the blanket. The flow rate in the divertor jets and the liquid in the back of the blanket are comparatively 
small. The mass flow rates and temperature are given in Fig. 4.

\section{Liquid wall design}

The liquid flows in from the top in Fig. 1 with a nominal downward speed of $10 \mathrm{~m} / \mathrm{s}$. In the case of flinabe there is also an azimuthal speed of about 10 $\mathrm{m} / \mathrm{s}$ to keep the liquid on the outer wall by centrifugal force as shown by $\mathrm{K}$. Gulec in related prior studies [Ref. 13, p 5-94 to 5-105]. In the case of $\mathrm{SnLi}$ and $\mathrm{Li}$, we assume the magnetic field will keep the flow closely following field lines.

The bulk of the liquid is heated mostly by neutrons by only $3^{\circ} \mathrm{C}$ for flinabe, $7.7^{\circ} \mathrm{C}$ for $\mathrm{SnLi}$ and $7.2^{\circ} \mathrm{C}$ for $\mathrm{Li}$ cases, as shown in Fig. 4. The line radiation from the core interior and the edge plasma and bremsstrahlung radiation from the core combine to heat the liquid near the surface. We need to determine the surface temperature in order to calculate the evaporation rate.

The evaporation rate is calculated from the following equations [10] and plotted in Fig. 5:

$J=\frac{n \bar{\nabla}}{4}=\frac{p}{(2 \pi m k T)^{0.5}}=C T^{-0.5} e^{(A-B / T)}$

Here $\mathrm{C}=3.828 \times 10^{23}$ for $\mathrm{BeF}_{2}$ evaporation and $9.961 \times 10^{23}$ for Li evaporation with values for A and B given in [10] except that $\mathrm{Li}$ values were erroneous there and should be $A=23.29$ and $B=18750$.

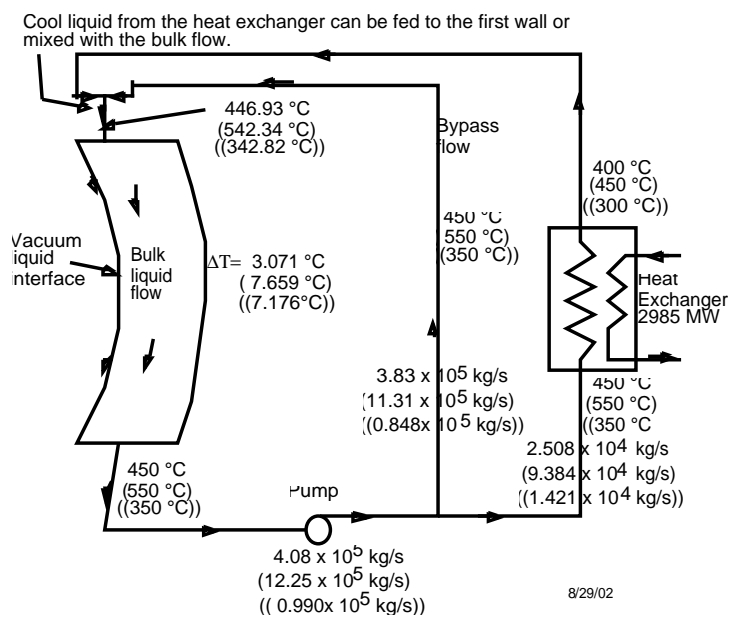

Fig 4. Mass flow and temperature diagram for flinabe with $\mathrm{SnLi}$ in parentheses and $\mathrm{Li}$ in double parentheses.

From Table 4, we get $0.05 \mathrm{MW} / \mathrm{m}^{2}$ of line radiation, surface heat load and $0.17 \mathrm{MW} / \mathrm{m}^{2}$ of bremsstrahlung radiation. For $\mathrm{SnLi}$, the surface heat load is assumed to be the same as for the flinabe case, $0.22 \mathrm{MW} / \mathrm{m}^{2}$. Photons of $10 \mathrm{keV}$ penetrate $\sim 1 \mathrm{~mm}$ into flinabe, whereas the film thickness where most of the temperature drop occurs is about $8.5 \mathrm{~mm}$.
The high Reynolds number (highly turbulent) flowing liquid with a free surface has eddies at the surface causing the surface to undulate. The transverse motion at and near the surface causes mass transport and, therefore, enhanced heat transfer beyond classical conduction. The equivalent thermal conductivity $\mathrm{k}_{\text {equivalent }}$ divided by the classical thermal conductivity $k$ has been calculated by Smolentsev [14]. The value of $k_{\text {equivalent }}$ is based on models discussed in [15] and plotted in Fig. 6 for flinabe for the flow speed of $10 \mathrm{~m} / \mathrm{s}$ and $0.5 \mathrm{~m}$ thickness. We take $\mathrm{k}$ to be $1.06 \mathrm{~W} \mathrm{~m}^{-1} \mathrm{~K}^{-1}$

We obtain the time averaged temperature profile by integrating the heat conduction equation:

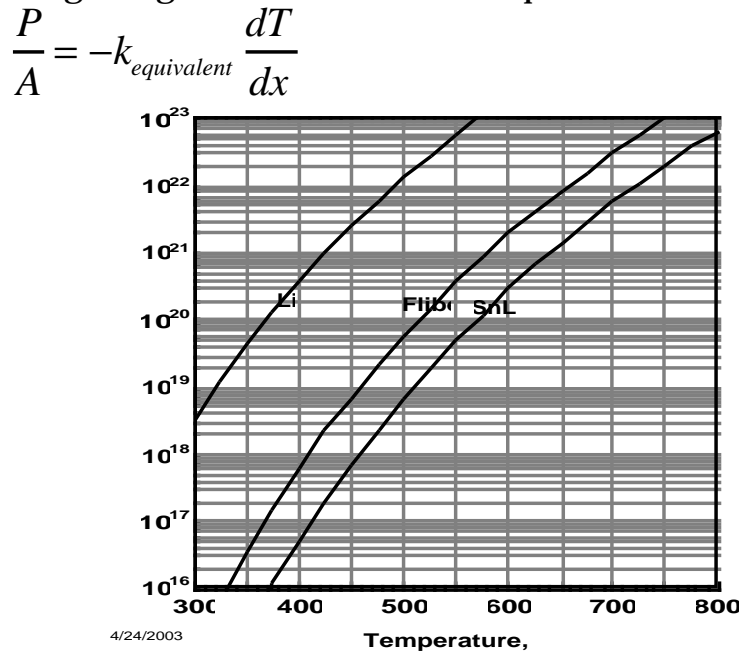

Fig. 5. Evaporation rates into vacuum for candidate liquids

Table 4

Liquid wall power flux and temperature parameters

\begin{tabular}{|l|l|l|}
\hline Type of power & MW & MW $/ \mathrm{m}^{2}$ \\
\hline Brem & 60.8 & 0.17 \\
\hline Line, core & 10.7 & 0.03 \\
\hline Line, edge & 7.6 & 0.02 \\
\hline Line, total & 18.3 & 0.05 \\
\hline Total & 79.1 & 0.22 \\
\hline $\begin{array}{l}\text { Charged power to } \\
\text { divertor }\end{array}$ & $\begin{array}{l}546(328 \text { to } \\
\text { lower } \\
\text { divertor })\end{array}$ & $\begin{array}{l}619 \\
28 \mathrm{~mm} \\
\text { flux tube }\end{array}$ \\
\hline \multicolumn{3}{|c|}{ Flinabe } \\
\hline$\Delta \mathrm{T}_{\text {film }}$ & $17^{\circ} \mathrm{C}$ & \\
\hline $\mathrm{T}_{\text {effective }}$ & $466^{\circ} \mathrm{C}$ & \\
\hline \multicolumn{3}{|l|}{$\mathrm{SnLi}$} \\
\hline $\mathrm{T}_{\text {film }}$ & $38^{\circ} \mathrm{C}$ & \\
\hline $\mathrm{T}_{\text {effective }}$ & $577^{\circ} \mathrm{C}$ & \\
\hline
\end{tabular}




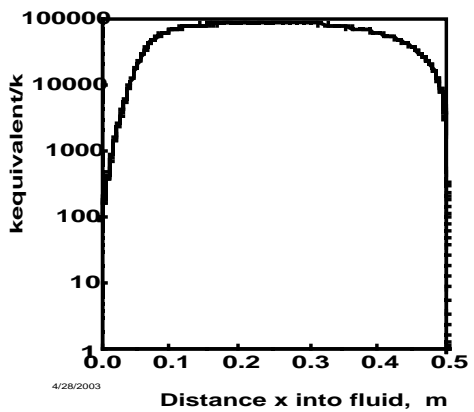

Fig. 6. Thermal conductivity for flinabe versus distance from the free surface into the flowing liquid.

where $\mathrm{P}$ is the incident power, $\mathrm{A}$ the area, and $x$ the normal distance into the liquid.

The solution is

$$
\Delta T_{\text {film }}=T(x=0)-T(x)=-\int_{0}^{x} \frac{P}{k_{\text {equivalent }} A} d x
$$

The integral using the variable equivalent thermal conductivity, from Fig. 6, is plotted in Fig. 7. The surface heat transfer coefficient, $h$, is $13,000 \mathrm{~W} / \mathrm{m}^{2} \mathrm{~K}$.

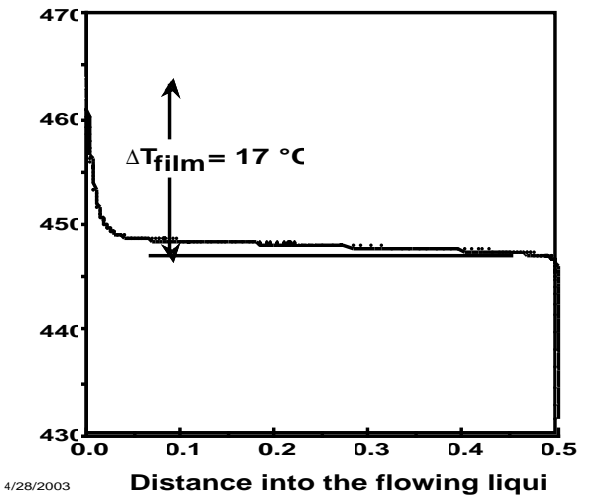

Fig. 7. Temperature profile through the flowing liquid. For a power density of $0.22 \mathrm{MW} / \mathrm{m}^{2}$ the film drop becomes $17^{\circ} \mathrm{C}$ for flinabe flowing at $10 \mathrm{~m} / \mathrm{s}$.

Because of the uncertainty of method used, we decided to do a large-eddy analysis and we get an estimate of the film temperature drop of $36{ }^{\circ} \mathrm{C}$ compared to the $\mathrm{K}-\varepsilon$ model [14] of $17{ }^{\circ} \mathrm{C}$. The two methods of calculating film temperature give some idea of the uncertainty, which is about a factor of two in film temperature drop.

For the flinabe case at $0.22 \mathrm{MW} / \mathrm{m}^{2}$ the surface temperature to use in evaporation estimates is some value between the inlet and outlet surface temperature. The inlet is $447^{\circ} \mathrm{C}$, from Fig. 4 . For this highly turbulent case, the surface quickly jumps by $17^{\circ} \mathrm{C}$, based on the previous discussion and shown in Fig. 7. Thus, the inlet temperature can be considered $(447+17) 464^{\circ} \mathrm{C}$. The outlet temperature is $3{ }^{\circ} \mathrm{C}$ higher than the inlet owing to neutron heating. Because of the strong turbulence and the neutron penetration distance of $\sim 0.1 \mathrm{~m}$, we assume no surface enhancement of temperature. Therefore, the outlet surface temperature is $467^{\circ} \mathrm{C}$. We weight the higher end and use an effective surface temperature of 466 ${ }^{\circ} \mathrm{C}$ in Tables 4 and 5.

\section{Liquid metal wall}

For the liquid metal cases of $\mathrm{SnLi}$ and $\mathrm{Li}$, we assume the motion is laminar because of the stabilizing effect of the magnetic field and use the classical conduction temperature rise formula:

$\Delta T_{\text {film }}=2 \frac{P}{A} \sqrt{\frac{t}{\pi k \rho C}}$

This equation gives the temperature rise as the surface flows from inlet to outlet while being heated with a surface heat load of $\mathrm{P} / \mathrm{A}$, in $\mathrm{W} / \mathrm{m}^{2}$. For our case, we take $10 \mathrm{~m} / \mathrm{s}$ and $15 \mathrm{~m}$ of path length or $1.5 \mathrm{~s}$ of exposure. The exit surface temperature equals the entrance temperature $+\Delta \mathrm{T}_{\text {film }}+\Delta \mathrm{T}_{\text {blanket }}$. Typically, we find the average evaporation occurs at a temperature about $3 / 4$ the total temperature rise. Call this temperature the effective temperature, $\mathrm{T}_{\text {eff }}$, i.e.,

$T_{\text {eff }}=T_{\text {inlet }}+\frac{3}{4}\left(\Delta T_{\text {film }}+\Delta T_{\text {blanket }}\right)$

For flinabe $T_{\text {eff }}=T_{\text {inlet }}+\Delta T_{\text {film }}+\frac{3}{4} \Delta T_{\text {blanket }}$

Table 5 Summary temperatures for liquid walls

\begin{tabular}{|l|l|l|l|}
\hline & Flibe & $\mathrm{SnLi}$ & $\mathrm{Li}$ \\
\hline$\Delta \mathrm{T}_{\text {film }},{ }^{\circ} \mathrm{C}$ & 17 & 38 & 22 \\
\hline $\begin{array}{l}\mathrm{T}_{\text {effectives }}{ }^{\circ} \mathrm{C} \\
\begin{array}{l}\text { (T-allowed from } \\
\text { impurity influx } \\
\text { analysis) }\end{array}\end{array}$ & 466 & 577 & 365 \\
\hline
\end{tabular}

The average evaporative flux from the wall for flinabe for $0.22 \mathrm{MW} / \mathrm{m}^{2}$ and a surface temperature of $466{ }^{\circ} \mathrm{C}$ is $1.4 \times 10^{19} \mathrm{~m}^{-2} \mathrm{~s}^{-1}$. The average evaporative flux from the wall for SnLi at $0.22 \mathrm{MW} / \mathrm{m}^{2}$ and a surface temperature of $577{ }^{\circ} \mathrm{C}$ is $1.3 \times 10^{20} \mathrm{~m}^{-2} \mathrm{~s}^{-1}$. The inlet temperature is $447^{\circ} \mathrm{C}$ for flinabe, $542{ }^{\circ} \mathrm{C}$ for $\mathrm{SnLi}$, and the exit surface temperatures are $467^{\circ} \mathrm{C}$ and $588^{\circ} \mathrm{C}$.

The predicted temperature of the liquid wall owing to radiation heating is lower than the allowed temperature owing to impurity contamination from evaporation as discussed in more detail in Impurity Contamination Section. The inlet temperature of the liquid wall apparently can be increased

\section{Divertor design}

The plasma lost across the separatrix flows along open field lines until it strikes the divertor surface as shown in Fig. 1. We plan to remove heat by injecting a set of high speed (up to $100 \mathrm{~m} / \mathrm{s}$ ) jets at a small angle to the magnetic flux, which guides the plasma flow. The jets are shown in a side-view and an endview in Fig. 8. The jets can be made to breakup into droplets if desired.

A vertical riser tube brings liquid up to inner and outer spray nozzles. These nozzles spray many rows 
of small jets ( $\sim .5 \mathrm{~mm}$ dia) or droplets ( $1 \mathrm{~mm} \mathrm{dia})$ to intercept the edge plasma. They carry away heat and provide surface area for condensation of evaporated material. The insulator must be protected from direct particle bombardment, either by a sufficiently dense stream or a low conductivity film on the surface.

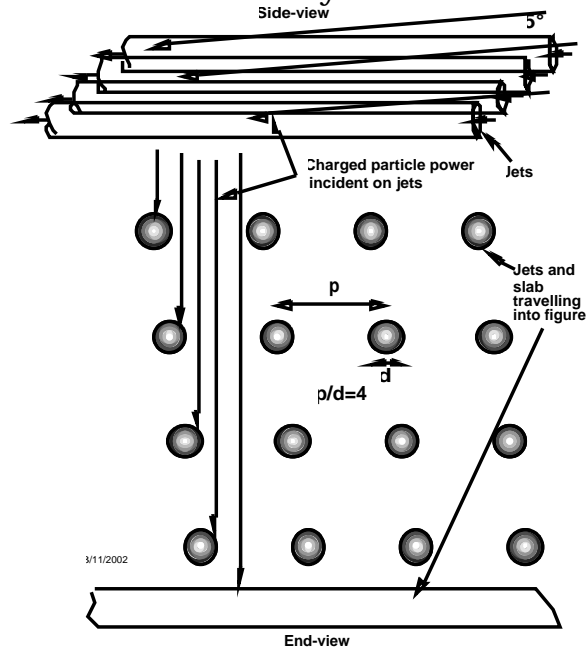

Fig. 8. Side-view and end-view of jets in the divertor are shown at $5^{\circ}$ to the flux.

The distance at the midplane of the separatrix $(\mathrm{R}=0)$ and the secondary (inactive) separatrix $(\mathrm{R}=6.0015 \mathrm{~m})$ is $1.5 \mathrm{~mm}$ as shown in Fig. 1. This flux tube at the jet divertor becomes $6 \mathrm{~mm}$ wide (at $\mathrm{r}=3 \mathrm{~m}, \mathrm{z}=-12 \mathrm{~m}$ ). If the leaking plasma that passes across the separatrix were to completely fill this $1.5 \mathrm{~mm}$ flux tube, all the power would flow to the divertor at the bottom. However, the calculated edge plasma profile has an e-folding width of $\sim 7 \mathrm{~mm}$. We estimate about $40 \%$ will flow out the top and through the aperture where the retractable electrode is shown in Fig. 1. The plasma flowing through this aperture would go into a large tank with sufficient room to spread out the heat. This needs to be analyzed in future design studies.

Sixty percent of the $546 \mathrm{MW}$ of leakage power, or 328 MW, is estimated to flow downward. The $7 \mathrm{~mm}$ wide plasma at the mid plane expands by a factor of four $(6 \mathrm{~mm} / 1.5 \mathrm{~mm})$ to $28 \mathrm{~mm}$ at the divertor, whose area is $(2 \pi 3 \mathrm{~m} \times 28 \mathrm{~mm}) 0.53 \mathrm{~m}^{2}$. The $328 \mathrm{MW}$ flowing into the bottom divertor then produces a power density of $619 \mathrm{MW} / \mathrm{m}^{2}$ over the $28-\mathrm{mm}$ wide flux tube. In future designs, the lower divertor may be expanded to carry the flux tube out to a larger area, as mentioned for the upper flux tube, thereby lowering the large power density. A factor of two expansion of the flux tube width together with a $5^{\circ}$ inclination to the B-field would give a $27 \mathrm{MW} / \mathrm{m}^{2}$ power density on the liquid surface. This becomes manageable with jets, which lower the effective heat flux by a factor of $\pi$ to $8.6 \mathrm{MW} / \mathrm{m}^{2}$ by averaging over the spinning jet surface.

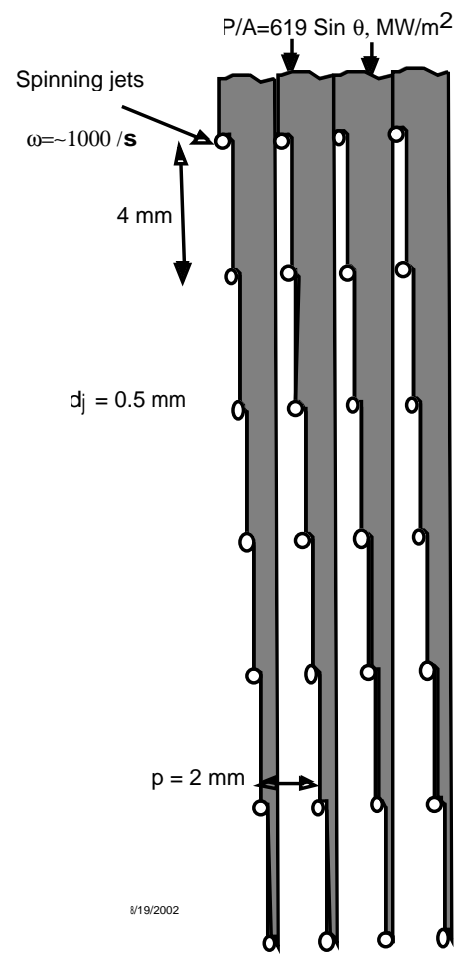

Fig. 9. The jets with a pitch to diameter ratio of 4 are shown. Seven rows of these jets are needed to intercept all the power.

We now investigate the evaporation rates for a liquid slab divertor and a jet divertor inclined at a small angle to the flow for a power density of $619 \mathrm{MW} / \mathrm{m}^{2}$. For a slab inclined at $5^{\circ}$-the smallest angle that seems possible with a flow speed of $100 \mathrm{~m} / \mathrm{s}-$ the average flux for flinabe is $6 \times 10^{27} \mathrm{~m}^{-2} \mathrm{~s}^{-1}$ and $4 \times 10^{22} \mathrm{~m}^{-2} \mathrm{~s}^{-1}$ for SnLi. Here, $T_{\text {in }}=673 \mathrm{~K}$ and $T_{\text {out }}=2249 \mathrm{~K}$ for flinabe and $T_{\text {in }}=723 \mathrm{~K}$ and $T_{\text {out }}=1118 \mathrm{~K}$ for SnLi. The flinabe case for slab geometry results in surface temperatures beyond the limits of validity of the analysis but is kept for comparison.

For four rows of jets $(\mathrm{p} / \mathrm{d}=4)$, as shown in Fig. 9, the analysis shows a reduced evaporation. The results are $1.74 \times 10^{23} \mathrm{~m}^{-2} \mathrm{~s}^{-1}$ for flinabe for $100 \mathrm{~m} / \mathrm{s}$ jets and $8.89 \times 10^{24} \mathrm{~m}^{-2} \mathrm{~s}^{-1}$ for $40 \mathrm{~m} / \mathrm{s}$ jets. For SnLi, the evaporation rate for $100 \mathrm{~m} / \mathrm{s}$ jets is $2.39 \times 10^{19} \mathrm{~m}^{-2} \mathrm{~s}^{-1}$ and for $40 \mathrm{~m} / \mathrm{s}$ jets is $1.77 \times 10^{20} \mathrm{~m}^{-2} \mathrm{~s}^{-1}$. The surface temperature at the exit for the first row is $1175 \mathrm{~K}$ for $100 \mathrm{~m} / \mathrm{s}$ and $1466 \mathrm{~K}$ for $40 \mathrm{~m} / \mathrm{s}$ flinabe. For SnLi, the surface temperature at the exit for the first row is 849 $\mathrm{K}$ for $100 \mathrm{~m} / \mathrm{s}$ and $922 \mathrm{~K}$ for $40 \mathrm{~m} / \mathrm{s}$ jets. The substantial reduction of the evaporative flux compared to the slab is due to the reduction by a factor of $\pi$ in average power and a factor of $\pi$ lower temperature rise. The surface temperature appears in the exponent of the evaporation equation.

In the next section we show the flux of impurities into the divertor are limited to $2 \times 10^{23}$ (particles $/ \mathrm{m}^{2} \mathrm{~s}$ ). The $100 \mathrm{~m} / \mathrm{s}$ flinabe jets meet this criterion but not 
the $40 \mathrm{~m} / \mathrm{s}$. The SnLi jets easily meet this criterion. For the slab, the flinabe does not meet this criterion even when the flux is expanded by a factor of 8 . The SnLi slab meets this criterion only at a speed of 100 $\mathrm{m} / \mathrm{s}$. At $40 \mathrm{~m} / \mathrm{s}$, the flux must be expanded by a factor of two.

Table 6 Evaporation from spinning jets $100 \mathrm{~m} / \mathrm{s}$ injection speed

\begin{tabular}{|c|l|l|l|l|l|l|}
\hline \multicolumn{3}{|c|}{} & \multicolumn{2}{c|}{ Flinabe } & \multicolumn{2}{c|}{$\mathrm{Li}$} \\
\hline $\begin{array}{l}\text { Row } \\
\#, \mathrm{n}\end{array}$ & $\begin{array}{l}\mathrm{P} / \mathrm{A}, \\
\mathrm{MW} / \mathrm{m}^{2}\end{array}$ & $\begin{array}{l}1 / 2 \times .785^{*} \\
(1-.25)^{\mathrm{n}-1}\end{array}$ & $\begin{array}{l}\mathrm{J}_{\text {jer, }} \\
10^{23} / \mathrm{m}^{2} \mathrm{~s}\end{array}$ & $\mathrm{~J}_{\text {net }}$ & $\begin{array}{l}\mathrm{J}_{\text {jet }} \\
10^{19} / \mathrm{m}^{2} \mathrm{~s}\end{array}$ & $\mathrm{~J}_{\text {net }}$ \\
\hline 1 & 197.0 & 0.3925 & 4.3750 & 1.7170 & 4.550 & 1.786 \\
\hline 2 & 98.5 & 0.2944 & 0.0222 & 0.0065 & 0.574 & 0.169 \\
\hline 3 & 98.5 & 0.2208 & 0.0222 & 0.0049 & 0.574 & 0.127 \\
\hline 4 & 98.5 & 0.1656 & 0.0222 & 0.0037 & 0.574 & 0.095 \\
\hline 5 & 98.5 & 0.1242 & 0.0222 & 0.0028 & 0.574 & 0.071 \\
\hline 6 & 98.5 & 0.0931 & 0.0222 & 0.0021 & 0.574 & 0.053 \\
\hline 7 & 98.5 & 0.0699 & 0.0222 & 0.0016 & 0.574 & 0.040 \\
\hline Total & & & & 1.7400 & & 2.390 \\
\hline
\end{tabular}

*The factor $1 / 2$ accounts for half of the evaporation being away from the divertor and the jet area of $\pi \mathrm{d}$ is a fraction of the total area; $\pi \mathrm{d} / \mathrm{p}=0.785$ for $\mathrm{p} / \mathrm{d}=4$.

\section{Impurity Contamination}

The plasma beyond the magnetic separatrix shields the core plasma from the impurities that evaporate from the liquid wall. Here we discuss the modeling of this scrape-off layer (SOL) plasma and present results on the effectiveness of the shielding. With respect to the liquid first-wall, the maximum flux of impurities that the SOL plasma can shield then determines the allowable surface temperature of the liquid. The surface is heated by a combination of bremsstrahlung and line radiation from the core and edge region (see Table 2). The heat flux to the divertor region is also important, because it defines what peak heat flux must be tolerated by the divertor. We use the self-consistent 2-D UEDGE transport code to calculate hydrogenic and impurity plasma profiles.

The model for the edge plasma considers the thin annulus of the edge region as a long-thin plasma slab. The X-points in the poloidal magnetic flux (see Fig. 1) are taken to be $10 \mathrm{~m}$ apart, and a divertor leg region of $2 \mathrm{~m}$ is used at each end. Because the toroidal magnetic field at the edge of a spheromak is small compared to the poloidal field, we take the Bfield to have only a poloidal component. We assume that the divertor leg regions can be designed to give low recycling of the hydrogen plasma, perhaps by drawing these field lines into a large dump tank. Thus, the hydrogenic recycling coefficient at the divertors is assumed to be $R_{h}=0.25$. At the separatrix, the density of the hydrogenic species (a 50/50\% mixture of deuterium and tritium) is taken to be $5 \times 10^{19} \mathrm{~m}^{-3}$, and power into the SOL is taken as 1.5 $\mathrm{MW} / \mathrm{m}^{2}$ divided equally between the ion and electron channels. The anomalous radial diffusion coefficients arising from plasma turbulence is $0.33 \mathrm{~m}^{2} / \mathrm{s}$ for density and $0.5 \mathrm{~m}^{2} / \mathrm{s}$ for electron and ion thermal energies.

The calculated radial plasma profiles at the outer midplane are shown in Fig. 10. The scale length of the density, $\mathrm{n}_{\mathrm{i}}$ and electron temperature, $\mathrm{T}_{\mathrm{e}}$, are very similar, both with a 1/e width of $8 \mathrm{~mm}$. The ion temperature has a characteristic high-temperature tail because the ion parallel thermal conductivity is much lower than that of the electrons

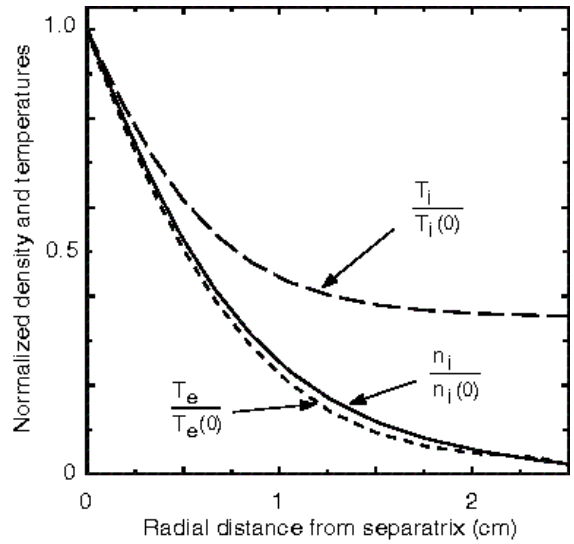

Fig. 10. Radial profiles of ion density, and electron and ion temperatures. Values at the separatrix are $\mathrm{n}_{\mathrm{i}}(0)=5 \times 10^{19} \mathrm{~m}^{-3}, \mathrm{~T}_{\mathrm{e}}(0)=676 \mathrm{eV}$, and $\mathrm{T}_{\mathrm{i}}(0)=702 \mathrm{eV}$. The input power from the core is $1.5 \mathrm{MW} / \mathrm{m}^{2}$.

The impurity gas coming from the liquid wall is modeled as a uniform flux along the radial boundary at $\mathrm{r}=6.025 \mathrm{~m}$ (which is $2.5 \mathrm{~cm}$ beyond the separatrix edge) at a temperature of $1 \mathrm{eV}$. More details on the transport model and the sensitivity of results for various assumptions is given in Ref. [16]. The impurities have the same anomalous radial diffusion coefficients as the hydrogenic species. The impurity ions that return to the side wall and those reaching the divertor plate through axial flow are assumed to be mostly reabsorbed into the liquid with a small recycling coefficient of $R_{\text {imp }}=0.25$. Values of $R_{\text {imp }}<0.5$ produce very similar results. We consider two impurity gas species, lithium and fluorine. Lithium is from either a pure lithium wall or a tin-lithium wall, either of which evaporates nearly all lithium. The second impurity gas considered is fluorine, which comes from the molten salts flibe or flinabe. Because fluorine has the highest charge of the atoms in these salts, it has the lowest allowable concentration at the core edge. The resulting impurity concentrations at the core edge are shown in Fig. 11. 


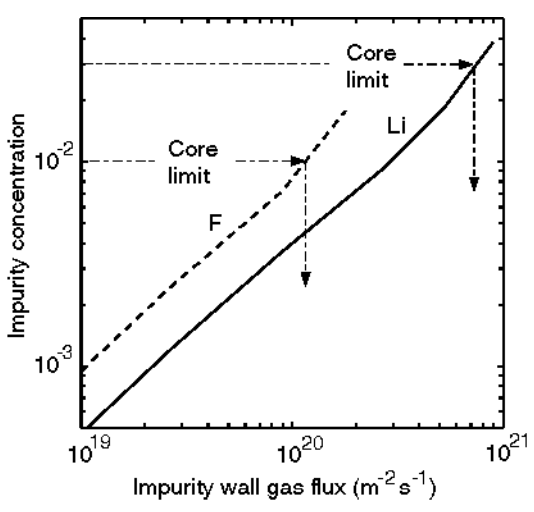

Fig. 11. Concentration of impurities $\left(n_{i m p} / n_{e}\right)$ at the separatrix for various liquid wall impurity gas fluxes distributed uniformly along the wall located $25 \mathrm{~mm}$ outside the separatrix.

Data from the vapor pressure of the various liquids versus temperature (see Fig. 5) are then used with a simple model to calculate the vapor flux. Using the limits of flux noted in Fig. 11, we arrive at the following wall temperature limits for three materials:

Table 7.

Maximum surface temperatures of liquid walls based on acceptable core impurity levels.

\begin{tabular}{|l|l|l|l|}
\hline Material & $\mathrm{Li}$ & $\begin{array}{l}\mathrm{SnLi} \\
(80 / 20)\end{array}$ & Flinabe \\
\hline $\begin{array}{l}\text { Surface } \\
\text { Temp. }{ }^{\circ} \mathrm{C}\end{array}$ & 410 & 630 & 520 \\
\hline
\end{tabular}

The heat flux at the divertor plate is very large in this simple slab model since it does not include any expansion of the magnetic flux surfaces shown in Fig. 1. For the cases considered here, the parallel heat flux is equal to the poloidal heat flux because there is no toroidal B-field. As a consequence, the peak flux is approximately $1.7 \mathrm{GW} / \mathrm{m}^{2}$.

This UEDGE result can be compared with the analysis presented earlier. There the flux tube area expanded from $7 \mathrm{~mm}$ by a factor of 4 to $28 \mathrm{~mm}$. Allotting for this increase in area, the UEDGE peak heat flux scales by $1.7 / 4$ to $425 \mathrm{MW} / \mathrm{m}^{2}$, which is reasonably consistent with the Table 4 values of 546 $\mathrm{MW} / \mathrm{m}^{2}$.

Sputtering and evaporation set the temperature limit of the divertor surfaces. The latter limit involves the sheath superheat phenomenon as studied for tokamaks $[17,18]$. Based on those studies, a rough evaporation-based limit for the present purposes is set by the condition that the evaporating impurity flux is approximately equal to the incoming hydrogen ion flux $[17,18]$. This flux ratio is, $G=$ (impurity atom flux)/(hydrogen ion flux). When $G$ $>>1$, (exact limit depending on surface material, flow velocity, and plasma parameters) the sheath collapses and runaway overheating of the surface occurs.

For our base-case of a low-recycling divertor, the peak hydrogen ion flux is $2 \times 10^{24} \sin \theta_{\tau}$ (particles $/ \mathrm{m}^{2}$ s), where $\theta_{\tau}$ is the tilt angle that the divertor stream makes with the B-field; $\theta=5^{\circ}$ for the design here. Thus, the rule of $\mathrm{G}=1$ implies that the maximum impurity flux is $2 \times 10^{23}$ (particles $/ \mathrm{m}^{2} \mathrm{~s}$ ). From curves of evaporative flux versus surface temperature for different materials shown in Fig. 5, such a flux corresponds to the following temperatures: for $\mathrm{Li}$, $\mathrm{T}=580{ }^{\circ} \mathrm{C}$; flibe/flinabe, $\mathrm{T}=740 \mathrm{C}$; for $\mathrm{SnLi}, \mathrm{T}=840 \mathrm{C}$, and for $\mathrm{Sn}, \mathrm{T}=1380 \mathrm{C}$. (For lithium, the sputtering limit is likely to be more restrictive). These results can be compared to those predicted from heat transfer. For flinabe, the evaporative flux predicted from heat transfer with rotating jets was $1.7 \times 10^{23}$ (particles $/ \mathrm{m}^{2} \mathrm{~s}$ ) for the $100 \mathrm{~m} / \mathrm{s}$ flinabe jet case. This case may be workable, but this subject needs more study.

For our base-case, the divertor surface is heated by a peak heat flux of $1 \times 10^{3} \sin \theta_{\tau}\left(\mathrm{MW} / \mathrm{m}^{2}\right)$ with a width of $0.7 / \sin \theta_{\tau}(\mathrm{cm})$. The peak temperature of the surface then depends on the conductivity of the liquid, which can be considerably enhanced by turbulence, especially for the low conductivity molten salts flinabe.

\section{Tritium breeding analysis}

The potential for tritium breeding is assessed for the spheromak shown in Figure 1. The radial blanket consists of $0.5 \mathrm{~m}$ thick fast-flowing liquid layer followed by $\sim 0.5 \mathrm{~m}$ thick slow-flowing liquid layer. Flinabe is considered in the present assessment, but a comparison of the adequacy of tritium breeding is also made for flibe. A design goal is to eliminate the presence of any neutron multiplier (e.g. beryllium) other than that already in the liquid in the radial blankets shown in Fig 1 due to the limitation of radiation damage lifetime and complexity. However, the top and bottom blankets could be designed as dedicated regions to supplement any additional tritium such that tritium self-sufficiency is achieved in the spheromak with the possibility of utilizing beryllium as a multiplier in these regions. Geometrically, the top and bottom regions occupy $\sim 7.5 \%$ each of the $4 \pi$ of the solid angle, while the radial blanket covers the remainder $(\sim 85 \%)$.

Without beryllium in the top and bottom blankets, the tritium breeding ratio (TBR) is marginal (TBR 1.05). There is a risk that TBR may fall below unity if more accurate 3-D calculation are made and account taken for nuclear data uncertainties. The TBR improves upon the utilization of a front Be zone in the top and bottom blankets. In this case, a TBR with comfortable margin is achieved. The TBR is $\sim 1.12$ when $100 \mathrm{~mm}$ thick beryllium zone is used in the top and bottom blankets and is $\sim 1.15$ with $200 \mathrm{~mm}$ Be zone.

\section{Conclusions and discussion}


This study examines a steady-state spheromak with a flowing liquid wall. We are sufficiently encouraged by the results to recommend further work on the concept if the core plasma energy confinement database improves. The database for spheromaks is reviewed in Ref. 19 and 20. However, for flinabe, the divertor evaporation is high (marginally meets our criteria) even with high speed jets $(100 \mathrm{~m} / \mathrm{s})$. The advantages of the simpler reactor embodiment of the spheromak (without toroidal coils and liquid walls replacing most of the solid first wall) are impressive.

To summarize:

- Evaporation from the walls, while high, is acceptable with some margin according to our analysis and criterion. Therefore, the temperature can be increased. The film-drop calculation used $0.22 \mathrm{MW} / \mathrm{m}^{2}$ surface heat load. Better estimates of surface temperature are needed. This requires better analysis and experiments on turbulent heat transfer.

- The evaporation in the divertor seems high but might be acceptable with some modifications. Even when the divertor is inclined at a small angle the power density of $620 \mathrm{MW} / \mathrm{m}^{2}$ becomes $54 \mathrm{MW} / \mathrm{m}^{2}$ on the liquid, which is still very large, resulting in very large evaporation rates. The use of spinning jets to average the power over the jet's surface gives an average heat load of $17 \mathrm{MW} / \mathrm{m}^{2}$, which approaches manageable values. The divertor needs further study and a solution for reducing the heat loads by perhaps expanding the flux surface by a factor of two or so.

- The gun threading magnetic flux is unusually small $(1 / 1000$ times the spheromak flux). Will this be realistically achievable?

- We should learn how to breed tritium without enriching the lithium and without adding solid beryllium to the blankets at the top and bottom.

\section{Acknowledgments}

*Work performed under the auspice of the U.S. Department of Energy by University of California Lawrence Livermore National Laboratory under Contract W-7405-Eng-48. This work is part of the Advanced Power Extraction (APEX) project sponsored by DOE Office of Fusion Energy Science. Support by Kyoto University, Institute of Advanced Energy is appreciated.

References

1. R.W. Moir, R.H. Bulmer, T.K. Fowler, T.D. Rognlien, M.Z. Youssef, "Thick liquid-walled spheromak magnetic fusion power plant," LLNL Report UCRL-ID-148021 Rev. 2 (2003).

2 P. M. Bellan, Spheromaks, Imperial College Press, London, 2000.

3 R. L. Hagenson and R. A. Krakowski, Fusion Technology 8, 1606 (1985).

4 L. J. Perkins, unpublished work on spheromak reactor designs (1995).
5 T. K. Fowler, D. D. Hua, E. G. Hooper, R. W. Moir and L. D. Pearlstein, "Pulsed spheromak fusion reactors," Comments on Plasma Physics and Controlled Fusion, Comments on Modern Physics, Vol 1 Part C 83-98 (1999).

6 E. B. Hooper and T. K. Fowler, "Spheromak reactor: Physics opportunities and issues," Fusion Tech., 30, 1390 (1996).

7 P. F. Peterson, UC Berkeley, private communications in a briefing (March 4, 2001).

8 E. B. Hooper et al., "MHD Equilibria in a Spheromak Sustained by Coaxial Helicity Injection," Nuclear Fusion 39 (1999) 863.

9 T. K. Fowler and E. B. Hooper, "Advanced Spheromak Fusion Reactor", submitted to the $8^{\text {th }}$ International Conference on Emerging Nuclear Energy Systems (Obninsk, Russia) June 24-28, 1996. Lawrence Livermore National Laboratory Report UCRL-JC-124363, June 19, 1996.

10 R. W. Moir et al., "Thick liquid-walled fieldreversed configuration-magnetic fusion power plant," Fusion Technology 39, 758-767 (2001).

11 J. Wesson, Tokamaks, Clarendon Press, Oxford (1987).

12 T. K. Fowler, D. D. Hua and B. W. Stallard, "Simulations of SSPX Sustainment -- Toward a Standard Model for Spheromaks," UCRLID141998, Jan. 12, 2001.

13 M. A. Abdou et al. "On the exploration of innovative concepts for fusion chamber technology," UCLA-ENG-99-206 (1999). Fusion Engineering and Design 54 (2001) 181-247.

14 S. Smolentsev, UCLA, private communications, November 13, 2001.

15 S. Smolentsev, M. Abdou, N. Morley, A. Ying, T. Kunugi, "Applications of the "K- $\varepsilon$ " model to open channel flows in a magnetic field," Int. J. Engineering Science, 40/6, 693-711 (2002).

16 T. D. Rognlien and M. E. Rensink, "Impurity transport in edge plasmas with application to liquid walls." Phys. Plasmas 9 (2002) 2120.

17 J.N. Brooks and D. Naujoks, "Sheath superheat transmission due to redeposition of thermally emitted material," Phys. Plasmas, Vol. 7 (2000) 2565.

18 D. Naujoks and J.N. Brooks, "Combined sheath and thermal analysis of overheated surfaces in fusion devices," J. Nucl. Mater., Vol. 290-293 (2001) 1123.

19 H. S. McLean, S. Woodruff, E. B. Hooper, R. H. Bulmer, D. N. Hill, C. Holcomb, J. Moller, B. W. Stallard, R. D. Wood, Z. Wang., Phys. Rev. Letters 88, 125004 (2002).

20 D. N. Hill, R. H. Bulmer, B. I. Cohen, E. B., Hooper, H. S. McLean, J. Moller, L. D. Pearlstein, D. D. Ryutov, B. W. Stallard, R. D. Wood, S. Woodruff, IAEA Conf., Lyon, France Oct. 2002, paper EX/C13. 